\title{
Como os grupos Balint têm mudado ao longo de 57 anos: objectivos e expectativas*
}

John Salinsky**

\section{RESUMO}

Objectivos: Descrever como a experiência de pertencer a um grupo Balint e os objectivos dos líderes dos grupos têm mudado, desde os anos 50, quando se iniciaram. Descortinar se os actuais grupos estão a responder às necessidades de desenvolvimento dos jovens médicos dos nossos dias.

Metodologia: O artigo descreve as alterações ocorridas nos grupos ao longo do tempo. A tentativa de formar os médicos de clínica geral de modo a tornarem-se psicoterapeutas deu lugar a um objectivo mais realista, que consiste em encorajar um estilo de consulta humanístico e empático. As necessidades dos médicos dos dias de hoje e os objectivos dos líderes dos grupos são examinadas e comparadas.

Conclusões: Os médicos ainda valorizam e beneficiam da oportunidade de falarem sobre as suas relações com os doentes. No entanto, é aconselhável que os líderes prestem mais atenção às preocupações e angústias específicas dos jovens médicos de hoje, pelo menos nos estádios iniciais.

\section{O INÍCIO DOS SEMINÁRIOS DE CLÍNICA GERAL}

À medida que começo a ler O Médico, o seu Doente e a Doença ${ }^{1}$, percebo muito nitidamente que um dos principais objectivos de Michael Balint era ensinar psicoterapia aos médicos de clínica geral. Michael Balint ouvia as histórias de casos que os médicos lhe traziam, tornando-se óbvio para ele que os problemas dos doentes eram psicológicos e que aquilo de que precisavam era de psicoterapia. Os doentes não tinham meios para pagar o «ouro puro» da psicanálise, pelo que era necessário que os médicos recebessem um pouco de «ouro» para acrescentarem aos «metais de base» da clínica geral. No final, esta abordagem revelou-se não realista e teve de ser revista. Felizmente, Balint tinha um segundo objectivo que contribuiu para encontrar uma solução. Os seminários eram descritos como 'treino-com-pesquisa' e a pesquisa consistia numa exploração qualitativa do que ocorria realmente na clínica geral. À medida que aprendia mais sobre o mundo da clínica geral, começou a compreender o que os médicos de família podiam fazer e o quanto já

*Comunicação apresentada no $15^{\circ}$ Congresso Internacional Balint, realizado em Lisboa entre os dias 1 e 5 de Setembro de 2007 (Traduzido do original inglês por João Paulo Brandão. Tradução revista por Cristina Ribeiro)

**Médico de Família inglês e ex-Secretário Geral da Federação Internacional Balint. faziam. Percebeu com mais nitidez o tipo de ajuda de que precisavam. Penso que Enid Balint deve ter tido um papel muito importante nestes desenvolvimentos e posso imaginar as discussões animadas que o casal terá tido em privado. Infelizmente não temos quase nada escrito sobre a contribuição de Enid para os grupos que co-liderou com Michael nesses primeiros tempos. Depois da morte de Michael, ela registou algumas das suas reflexões de que eu falarei adiante.

\section{O QUE QUERIAM OS MEMBROS DOS GRUPOS?}

Entretanto, gostaria de dizer algo sobre os objectivos dos membros dos grupos. Julgo que, ao longo dos cerca de 57 anos da nossa história, tem subsistido uma tensão, uma tensão criativa, se quisermos, entre os objectivos dos líderes dos grupos e os objectivos dos membros dos grupos. Hoje em dia ensinam-nos a estarmos atentos às 'ideias, preocupações e expectativas' dos nossos doentes. Mas quais eram as ideias, preocupações e expectativas dos médicos de clínica geral nos grupos Balint nos anos 50 ? É evidente que eu não estava lá para presenciar, mas tive o privilégio de conhecer e de trabalhar com várias pessoas que pertenceram a esses grupos pioneiros. Também descobri alguma informação histórica útil em A Study of Doctors ${ }^{2}$ (Balint et al, 1966). 
O que é que os médicos de clínica geral queriam dos seminários nos inícios dos anos 50 ? Sabemos que um número substancial de participantes abandonou os seminários passado um ano ou menos, claramente por estarem saturados da experiência. ${ }^{2}$ Para alguns, a ausência de uma instrução formal era motivo de insatisfação. Outro subgrupo, que Michael denominava de 'o dos médicos superiores' incluía médicos que estavam mais interessados em falar sobre os seus métodos e não queriam aprender nada de novo. E outros havia que no fundo estavam à procura de terapia para si mesmos, quer o soubessem quer não. Alguns dos médicos que ficaram talvez estivessem à procura de uma formação rápida e «indolor» em psicanálise. Estes, faziam interpretações arrojadas e eram bem versados em terminologia psicanalítica. Embora os líderes não abrissem os braços à chegada dos termos técnicos, encorajaram estes médicos a continuarem os seus esforços, já que 'fazer psicoterapia' constituía ainda o objectivo dos primeiros seminários. Os restantes não se viam como psiquiatras potenciais, nem certamente como amadores. Estavam simplesmente frustrados pela sua incapacidade de compreenderem as necessidades de muitos dos seus doentes perturbados e desejavam aprender a ajudá-los de uma forma prática.

\section{A FUNÇÃO APOSTÓLICA}

A minha impressão é que os Balint estavam a mudar de ideias sobre os objectivos dos seminários mesmo durante o tempo em que Michael escrevia o seu célebre livro (publicado em 1957). Se observarmos os últimos capítulos, particularmente os dois sobre «A Função Apostólica» e «O médico e o seu paciente», descobrimos evidências desta reavaliação. Michael diz que todos os médicos têm personalidades muito diferentes e que estas irão determinar as suas abordagens terapêuticas. Alguns dão conselhos, que poderão ou não ser seguidos. Alguns são observadores distanciados, enquanto outros se preocupam tanto que se transformam em pais. Alguns são autoritários e prescritivos, enquanto outros são gentis e reconfortantes. Alguns são extremamente tolerantes em relação a doentes grosseiros ou ingratos. Alguns têm uma curiosidade psicológica, enquanto outros preferem não fazer perguntas íntimas. Assim, conclui Michael, no final, independentemente do que lhes digamos, cada um tratará os seus doentes de forma particular. Felizmente, as condições particulares da clínica geral permitiam aos médicos agirem de forma própria e atraírem os doentes a quem o seu estilo melhor se adequava. E, poderia ter acrescentado Michael, pelo menos ensinei-os a escutar.

\section{A ENTREVISTA LONGA}

Como é que ele o conseguiu? Penso que a resposta reside na Entrevista Longa, que na altura era essencial. Ninguém se atreveria a apresentar um caso sem ter primeiro passado pelo menos uma hora com o doente. $\mathrm{Na}$ entrevista longa, livre das pressões de ter que ver um doente a cada cinco minutos, o médico poderia finalmente dar ao doente a sua total atenção e, igualmente importante, prestar alguma atenção aos seus próprios sentimentos. Qualquer médico que tenha experimentado efectuar uma entrevista longa sabe a revelação que isso pode constituir. O doente desabrocha de repente, surgindo como um ser humano, capaz de falar sem restrições sobre a sua vida e as suas emoções. Mas o que vem a seguir? Será esta apenas a primeira de uma longa série de sessões psicoterapêuticas? Como terminará este processo? E que fazer com os outros doentes?

No final dos anos 50, muitos dos leais médicos dos seminários, embora gratos aos Balint pelo que tinham conseguido alcançar com os seus doentes seleccionados, começavam a preocupar-se com todos os outros, que ainda recebiam apenas consultas de cinco ou dez minutos. Não parecia ser justo limitarem os seus novos conhecimentos e métodos a uns poucos doentes eleitos. ${ }^{5}$

\section{SEIS MINUTOS: A SEGUNDA FASE}

Em Janeiro de 1966, um novo e revolucionário grupo começou em Londres. Era liderado por Michael e Enid e a sua missão era tornar possível a realização de trabalho Balint dentro do contexto de uma consulta normal de 10 a 15 minutos. Nesta altura, Michael declarou a Entrevista Longa um 'corpo estranho' sem lugar na clínica geral. ${ }^{4}$ Tinha chegado o momento de os médicos deixarem de ser detectives à procura da solução para o mistério da condição de um doente. Em vez disso, os médicos tentariam captar os sentimentos dos doentes, colocar-se no seu lugar ou, como agora se diz, empatizar com o doente. Os Balint nunca utilizaram esta palavra, mas Enid falou da necessidade de se identificar 
com o doente - distanciando-se em seguida para o poder observar objectivamente. ${ }^{7}$ Por vezes, os membros dos grupos e os seus doentes experimentavam um momento clarificador de entendimento mútuo, que se tornou conhecido como 'o flash'. Infelizmente, o flash foi sempre muito difícil de vivenciar, pelo que, rapidamente, saiu do vocabulário Balint.

A mudança verdadeiramente importante introduzida por este grupo foi, a meu ver, a ideia de que uma uma mudança no modo como o médico se sentia em relação ao doente era tão importante como uma mudança no doente. Afinal de contas, muitos doentes não queriam mudar. Preferiam agarrar-se às suas defesas, aos seus sintomas e aos seus estilos de vida auto-destrutivos. O que queriam era um médico com alguma compreensão sobre o modo como se sentiam. Um médico que estava preparado para ouvir e partilhar o peso quando se sentiam sós e miseráveis; um médico que talvez fizesse algumas observações, mas que não ousaria dar-lhes conselhos que não queriam ou não podiam utilizar. E, talvez, pelo menos alguns deles ficassem motivados, através desta contenção da sua aflição, a iniciar por si mesmos o processo de mudança. É certo que Enid adoptou esta perspectiva optimista, sendo assim que começámos a ouvir a ideia de que um médico de clínica geral se poderia prestar a ser usado (o que antes seria impensável) da forma que o doente precisasse. Os líderes começaram a perguntar: que tipo de médico é que este doente precisa que o seu médico seja?

Também perguntavam ao grupo: 'como é que acha que será ser-se este doente?’ De forma a encorajar o processo crucial de identificação ou empatia.

Apesar de Michael Balint ter morrido em Janeiro de 1970, o grupo continuou durante mais um ano sob a liderança de Enid e o seu trabalho encontra-se resumido no livro Six Minutes for the Patient. Ou, como é conhecido na Alemanha, «Cinco minutos para o doente». Muitos dos médicos no grupo sentiram-se aliviados ao saberem que já não era necessário negligenciarem as vidas emocionais da maioria dos seus doentes de forma a favorecem uns poucos. Um ou dois sentiu muito intensamente a falta da entrevista longa e um médico (Philip Hopkins) apresentou um relatório minoritário, declarando que iria continuar da forma antiga, que tanto tinha feito por si e pelos seus doentes.

\section{A NOSSA LINGUAGEM É INTERNACIONAL?}

Estas ideias continuaram a ganhar terreno e a desenvolver-se na Grã-Bretanha durante os anos 70 e 80 . Tenho a certeza de que o mesmo processo decorreu em grupos Balint noutros países da Europa. Poderão perguntar-me como é que eu posso estar tão seguro de que evoluímos em paralelo, uma vez que não sei alemão e quase nada de francês, e muito menos outros idiomas. No entanto, durante dez anos fui secretário da Federação Internacional Balint. Participei em grupos (em inglês) em muitos países nos últimos vinte anos e senti-me sempre como se estivesse em casa. A linguagem Balint parece ser internacional.

\section{NÃO É NECESSÁRIO DIZER AO DOENTE}

$\mathrm{Na}$ Grã-Bretanha, embora não tivéssemos muitos grupos, houve um núcleo activo de membros entusiásticos da Sociedade Balint que continuaram a encontrar-se e a discutir as suas ideias. Outros grupos de pesquisa relataram os seus trabalhos em While I'm here, doctor $(1987)^{5} \mathrm{e}$ The doctor the patient and the group $(1993)^{6}$. Ambos os grupos eram liderados pela Enid e continuaram, de formas diferentes, a desenvolver a ideia do médico como observador que, depois de tanto experimentar os seus sentimentos como os do doente, se distancia de forma a organizá-los ou a dar-lhes um sentido. Aconteceu outra coisa muito importante. Os médicos deixaram de tentar transmitir ao doente as suas conclusões. Por outras palavras, deixaram de fazer interpretações. Finalmente tinham deixado de pretender ser psicoterapeutas. Talvez tivessem crescido.

O nosso mais recente livro, What are you feeling $\operatorname{doctor}^{7}$ (2000), foi o primeiro a descrever trabalho feito sem a presença de um psicanalista. Ambos os líderes eram médicos de clínica geral. E, no entanto, em muitos aspectos é o livro mais analítico de todos, já que os médicos fizeram um maior esforço de introspecção e de análise das suas próprias defesas. O objectivo terapêutico era agora tentar ajudarem-se a serem mais receptivos aos sentimentos dos doentes e a não travarem as suas respostas emocionais quando as coisas se tornavam um pouco mais dolorosas

\section{O QUE SE ESTÁ A PASSAR AGORA?}

Volto a referir que só posso dar testemunho daquilo que se passa no meu país. Não me surpreende, no entanto, 
se as vossas experiências forem semelhantes. Ainda não temos muitos grupos Balint, mas apraz-me dizer que se estão a tornar mais numerosos. Temos muitos grupos para médicos de clínica geral em formação, temos um número crescente de grupos para médicos veteranos $\mathrm{e}$ temos alguns grupos para estudantes. Devo voltar às minhas duas questões: o que querem os líderes e o que querem os membros dos grupos? Será que querem a mesma coisa/se não, porquê? (São quatro questões).

\section{O QUE QUEREM OS MÉDICOS VETERANOS}

Apraz-me dizer que um número crescente de médicos de clínica geral estabelecidos tem vindo a contactar a nossa Sociedade Balint para saberem como podem aderir a um grupo. Dizem-nos que querem voltar a falar de medicina pessoal. Estão desiludidos com a actual tendência de impiedosa recolha de dados e de «sinalização em caixas». No entanto, os doentes problemáticos e exigentes ainda não desapareceram e o grupo Balint é visto como um espaço onde os médicos podem descarregar as suas angústias. Talvez tenha sido sempre assim. De qualquer forma, ouvimos falar muito de stress e de burn- out, da necessidade de apoio e da necessidade de se ser ouvido. Os médicos querem compreender melhor o doente, mas numa óptica de «porque é que ele me está a fazer isto? Como é que eu o posso impedir?». Existe alguma dificuldade de adesão ao processo de identificação e empatia. Os médicos parecem estar a dizer: deixem-me entrar para me lavar depois do meu dia de combate. Deixem-me deitar-me e contar-vos o que se passou comigo até me sentir melhor. Parece psicanálise! Os líderes trabalham arduamente para deixar transparecer alguma empatia: «OK, esta doente está a dar-lhe trabalho,' dizemos, 'mas como é que ela se sente quando vai para casa? Que tipo de vida está a viver? Como é que ela se sente em relação a si mesma e ao médico?»'. Então obtemos uma resposta. Talvez tenha continuidade, talvez não. Por vezes voamos, de outras vezes caímos e não conseguimos descolar.

\section{O QUE QUEREM OS FORMANDOS?}

Ao observarmos os grupos de formandos na Grã-Bretanha a situação é diferente, uma vez que não existem grupos de voluntários. Estes soldados foram recrutados. Inscreveram-se num plano de formação em clínica geral que, embora não o soubessem, inclui um grupo Ba- lint uma vez por semana. Todos eles estão a fazer a difícil transição do trabalho hospitalar para a comunidade. Até agora nunca ouviram falar de Balint. Estes médicos disponibilizam-se para apresentar doentes, mas estes são geralmente pessoas em relação às quais têm sentimentos muito negativos.

Eis alguns exemplos de apresentações típicas de formandos:

- Alguém que os faz sentir inferiores e inadequados. Neste ponto ainda se sentem inseguros como médicos. Ainda não compreenderam que alguns doentes se sentem melhor ao projectarem no médico os seus sentimentos indesejados, deixando-o a sofrer.

- Alguém que os faz sentirem-se insuficientementecompetentes ou aptos do ponto de vista psicológico: talvez uma jovem com anorexia ou um casal com um casamento em declínio.

- Doentes que afrontam a noção que o formando tem sobre o modo como um doente se deve relacionar com um médico. Estou a pensar em pessoas que pedem 'atestados' quando não estão doentes (pelo menos segundo o médico); pessoas que pedem cartas exigindo que lhes seja dado um sítio melhor onde viver, um empréstimo, um cartão de residência para um familiar, ou mesmo a expectativa de evitarem uma pena na prisão.

- Alguns doentes ofendem ao se recusarem a seguir os conselhos do médico. Não deixam de fumar nem passam a comer menos gorduras, não fazem exercício físico, não mudam o seu estilo de vida. Não tomam a medicação indicada e pedem medicamentos que nós consideramos desadequados (como antibióticos ou hipnóticos).

Os nossos jovens médicos têm uma grande dificuldade em se identificarem com estes doentes. Não se querem pôr no seu lugar nem por um segundo. Viram-se para os seus colegas procurando criar uma estratégia que os ajude a ganhar a batalha. Devo confrontar esta doente? Devo dizer-lhe que não a verei mais a menos que... Devo orientá-la para outro médico? Será que tenho mesmo que lhe passar a carta? Se calhar não estou a ser suficientemente firme. Quero simplesmente saber o que fariam outros médicos.

Os líderes dizem coisas como: sim, mas como será que o doente se sente? O que é que o leva a ter esse comportamento? Há alguma coisa nele que você goste? Não 
será que leva uma vida miserável? Porque é que está tão zangado com ele? Não haverá uma parte de todos nós que também gostaria de tomar uns comprimidos mágicos ou ficar na cama em vez de ir para o trabalho?

É evidente que alguns dos nossos membros dos grupos aderem mais rapidamente à ideia de um estilo de medicina empático e humanitário. E no final do ano pelo menos alguns fizeram uma tentativa nesse sentido. Entretanto, outros mantêm-se invulneráveis ou chegam a afastar-se do grupo, que não lhes parece ter um objectivo.

Este desencontro entre as expectativas dos líderes e dos membros foi descrito num recente estudo de um grupo de formandos Balint dirigido por Ruth Pinder. ${ }^{8}$ Ela concluiu o estudo perguntando como é que o Balint se poderá adaptar a estes tempos em mudança sem perder os seus valores nucleares. Penso que se deverá levar a pergunta a sério porque, pelo menos no Reino Unido e provavelmente em todo o lado, a nossa abordagem não parece estar a responder aos problemas que os nossos jovens médicos enfrentam. Eles sabem tudo sobre ficarem condicionados com doentes difíceis mas não querem jogar à identificação com o doente. Fazer a identificação com o doente é uma técnica ou um jogo que eles não estão interessados em jogar.

\section{CONCLUSÃO}

Penso que temos de escutar com atenção o que pesa nas mentes dos nossos jovens membros dos grupos à medida que eles descobrem o tipo de médicos em que se querem tornar. Tal como os Balint escutaram atentamente os membros dos grupos originais há mais de 50 anos. Talvez devamos estar disponíveis para deixar entrar no grupo alguns dos indivíduos que nos parecem mais à margem. Devemos ter interesse em tudo aquilo que põe os médicos sob pressão, incluindo as dificuldades com formandos e tutores e o sistema de saúde como um todo. Devemos estar preparados para pensar porque é que tantos tipos de comportamento dos doentes parecem inaceitáveis e mesmo ameaçadores. $\mathrm{Ou}$, como diria Ruth Pinder, devemos reflectir sobre a cultura. E quando toda essa angústia tiver sido aceite, contida e organizada, poderá chegar o momento de começarmos a divulgar a ideia de que esses doentes horríveis não são assim tão diferentes de nós mesmos.

\section{REFERÊNCIAS BIBLIOGRÁFICAS}

1. Balint M (1957) The Doctor, his Patient and the Illness London:. Pitman; 1957.

2. Balint M, Balint E, Gosling R, Hildebrand P.A Study of Doctors. London: Tavistock; 1966.

3. Salinsky J, Courtenay M. An interview with Michael Courtenay. J Balint Soc 2004; 32: 6-10.

4. Balint E, Norell J, editors. Six Minutes for the Patient: interactions in general practice consultation. London: Tavistock; 1973.

5. Elder A, Samuel O, editors. (1987) While I'm Here, Doctor: a study of the doctor-patient relationship. London: Tavistock; 1987.

6. Balint E, Courtenay M, Elder A, Hull S, Julian P. The Doctor the Patient and the Group: Balint revisited. London: Routledge; 1993.

7. Salinsky J, Sackin P.What are you Feeling, Doctor? Identifiying and avoiding defensive patterns in the consultation. Oxford: Radcliffe Medical Press; 2000.

8. Pinder R, McKee A, Sackin P, Salinsky J, Samuel O, Suckling H. Talking about my Patient. Occasional Paper Nr 87. London: Royal College of General Practitioners, Londres; 2006.

\footnotetext{
ABSTRACT

Aims: To describe the ways in which the experience of being in a Balint group and the objectives of the group leaders have changed since the groups began in the 1950s. To discover whether today's groups are meeting the developmental needs of today's young doctors.

Methodology: The article traces the changes in the groups over time. The attempt to train GPs to be psychotherapists gave way to a more realistic aim of encouraging empathic, humanitarian style of listening. The needs of present day doctors and the aims of the group leaders are then examined and compared.

Conclusions: Doctors still value and benefit from the opportunity to talk about their relationships with patients. However, the leaders may need to pay more attention to the particular concerns and anxieties of today's young doctors at least in the early stages.
} 